\title{
Demanding applications in harsh environment - FeCrMnNiC amorphous equiatomic alloy thin film
}

\author{
W. Muftah*, N. Patmore and V. Vishnyakov \\ Institute for Materials Research, University of Huddersfield, HD1 3DH, UK
}

\begin{abstract}
An amorphous equiatomic $\mathrm{FeCrMnNiC}$ alloy thin film was synthesised on silica and silicon substrates by ion beam sputter deposition. Scanning Electron Microscopy (SEM) Energydispersive X-ray spectroscopy (EDX), X-Ray Diffraction (XRD), Selected Area Electron Diffraction (SAED) and Nano indentation were used to investigate the material. The produced film is amorphous and uniform on the atomic level without any detectable element segregation. The corrosion properties were assessed in $3.5 \% \mathrm{NaCl}$ solution. The FeCrMnNiC alloy has corrosion resistance better than corrosion resistance of $304 \mathrm{SS}$. The thin film has hardness at around $12.3 \pm 0.5 \mathrm{GPa}$ and reduced Young's modulus at around $222 \pm 12 \mathrm{GPa}$.
\end{abstract}

\section{Keywords}

FeCrMnNiC, equiatomic alloy, high entropy alloy HEA, amorphous, thin film, microstructure, corrosion resistance, hardness

*) Corresponding author: Waleed Muftah, Waleed.Muftah@hud.ac.uk 


\section{Introduction}

Demands for growth in efficiency, longer lifespan and emerging new applications all require development of more advanced alloys. Metal alloy properties are traditionally refined along the lines of atomic compositions and grain/boundary morphologies. The contemporary advance started with multicomponent alloys and then realisation that the entropy of mixing can be exploited as an engineering properties enhancement tool. [1-3]. The configurational entropy in this case is maximised at the equiatomic concentrations. The equiatomic alloys, from the entropy point of view, form a subset of highly concentrated alloys and are also known as High Entropy Alloys (HEA's). [4]. Classically, it is thought that HEA's are defined as the alloys which contain five or more principle elements with close to equiatomic ratios. [3-5]. High configuration entropy effects can be of lower magnitude but still beneficial with less than five elements or when atomic concentrations can be not exactly equal. For example, high entropy properties enhancement effects have been claimed at concentration between 35 and 5 at.\% of principle elements [3]. Many more papers claim high entropy effects with broadly fluctuating element concentration and even partial element segregations.

Numerous experiments have reported that high entropy alloys exhibit simple crystal structure and demonstrate enhanced properties such as: high hardness, high toughness, high temperature softening resistance and high resistance to wear and corrosion. [2]. High entropy alloys are produced by mixing many different elements from the "traditional engineering" subset such as: $\mathrm{Fe}, \mathrm{Al}, \mathrm{Mn}, \mathrm{Ni}, \mathrm{Co}, \mathrm{Cu}, \mathrm{Cr}, \mathrm{Ti}$ and $\mathrm{Mg}$ [6]. In many cases high value elements are used too but, probably, the above is the most attractive set from the points of price and omnipresence. Several processing techniques have been widely used to produce high entropy alloys like: melting and casting, powder metallurgy and deposition techniques such as magnetron sputtering. [7].

It is very difficult to satisfy all engineering requirements for a particular application in a single alloy. Many mechanical properties depend on grain structure and carefully constructed grain boundaries. At the same time, unless carefully constructed, the grain boundaries are prone to oxidation, corrosion and erosion. It is beneficial to have just amorphous (glassy) alloys in a knowledge that at the application conditions the element segregation and/or crystallisation would not proceed and the alloy properties would not deteriorate substantially over the service time. For reasons other than mechanical properties, significant work has been done in the amorphous alloys area. Amorphous alloys at the point of creation are uniform structurally. However, most of the amorphous alloys are not in thermodynamic equilibrium at room and

elevated service temperatures. This manifest itself in relaxation processes as the alloys try to reach thermodynamical equilibrium. From the macroscopic point of view this manifest itself, for instance, in changes in electrical conductivity and ductile-to-brittle transitions. An excellent review has been produced recently by Ruta et al [8].

Amorphous alloys are also known as metallic glasses, bulk metallic glasses or non-crystalline alloys. They were first reported by Klement et al, in 1960, for the $\mathrm{Au}_{75} \mathrm{Si}_{25}$ system. [9]. Traditionally, amorphous alloys are produced by alloy rapid quenching from the liquid or vapour state [10-12]. This quenching "freezes" atomic structure in random uniform state. In the absence of grains, amorphous alloys do not have grain boundaries and do not have "weak 
spots" seen in traditional metals [13]. It is also known that the grain boundary absence enhances resistance to corrosion. $[14,15]$. It is beneficial then that some high entropy alloys can be amorphous $[16,17]$. These types of materials have excellent mechanical properties, as seen in $\mathrm{Fe}_{25} \mathrm{Co}_{25} \mathrm{Ni}_{25}(\mathrm{P}, \mathrm{C}, \mathrm{B}, \mathrm{Si})_{25}$ [18], and have high fracture strength, as observed for $\mathrm{Ti}_{20} \mathrm{Zr}_{20} \mathrm{Cu}_{20} \mathrm{Ni}_{20} \mathrm{Be}_{20}$ [19]. However, there is limited number of studies into the corrosion properties of amorphous HE alloys.

Thin film materials allow delivery of necessary properties at the surface, where they are in many cases most needed. Thin films also excel in at least two areas; they can attain unique properties not achievable in bulk materials, and economise on scarce and expensive elements. $[20,21]$.

Most of the studies of high entropy bulk alloys has been carried out on the study of their mechanical properties, strength, ductility, hardness and corrosion. [22]. In addition, nonequiatomic or/and multiphase transition metal HEAs showed good properties in many cases for instance; $\mathrm{AlCoCrFeNi}_{2.1}$ [23], $\mathrm{CoCrFeNi}_{2.1} \mathrm{Nb}_{\mathrm{x}}$ [24], $\mathrm{Fe}_{50} \mathrm{Mn}_{30} \mathrm{Co}_{10} \mathrm{Cr}_{10} \mathrm{C}_{0.5}$ [25], $\mathrm{Fe}_{80-x} \mathrm{Mn}_{x} \mathrm{Co}_{10} \mathrm{Cr}_{10}$ and $\mathrm{Co}_{20} \mathrm{Cr}_{20} \mathrm{Fe}_{40-y} \mathrm{Mn}_{20} \mathrm{Ni}_{y}$ [26], which exhibited excellent strengthductility combinations. Only some studies have focused on the synthesis and corrosion resistance of high entropy thin film prepared by magnetron sputtering technique, for example, studies on AlTiCrNiTa [27], and by laser cladding, such as seen in CrMnFeCoNi [28], $\mathrm{Al}_{2} \mathrm{CrFeCo}_{\mathrm{x}}$ [29]. In general, so far, the materials displayed inferior corrosion properties in a comparison with 304 SS. Stainless steel (304 SS) is been widely used by researchers as a reference against the most of new produced materials, as it has a high corrosion resistance, and well-known corrosion behaviour [30-33].

Adding metalloids such as carbon in a large amount to produce the amorphous state to the alloy enhances corrosion resistance [34]. Moreover, experiments on (CrNbTaTiW)C multicomponent carbide thin films (30-40 at. \% of C) carried out by magnetron sputtering showed excellent corrosion resistant and better than stainless steel reference material [35].

In this paper, we report the synthesis and corrosion resistance of a new equiatomic amorphous high entropy thin film alloy based on five elements: Fe, $\mathrm{Cr}, \mathrm{Mn}, \mathrm{Ni}$ and $\mathrm{C}$. Elements were chosen based on published and desirable properties. Iron for instance, is the principle element in majority of HEAs due to its wide availability and its high miscibility with many other elements. $\mathrm{Cr}$ and $\mathrm{Ni}$ have good corrosion resistance, $\mathrm{Mn}$ to is used in many cases to harden an alloy. In addition, (Fe, $\mathrm{Cr} \& \mathrm{Ni}$ ) combination is used in more than $70 \%$ of HEAs. Carbon was chosen to increase the alloy harness and enhance corrosion resistance. The whole FeCrMnNiC alloy is a new one and has not been investigated and reported yet by the colleagues. Ion Beam Sputter Deposition technique was used to prepare the alloy. SEM, EDX, XRD, and SAED were used to characterise the presented alloy. An electrochemical cell using a three-electrode set up was used to study corrosion resistance of $\mathrm{FeCrMnNiC}$ alloy against $304 \mathrm{SS}$.

\section{Materials and methods}

The thin film alloy was synthesised by an ion beam sputter deposition system [36] from a composite target of $\mathrm{FeCrMnNi}$ and an elemental target of $\mathrm{C}$. The deposition was done on a 
Silica substrate at room temperature without heating. The base system pressure was $2.2 * 10^{-4}$ $\mathrm{Pa}$, and the Ar partial pressure in the deposition chamber during the deposition was $3.4 * 10^{-2}$ $\mathrm{Pa}$ (pressure was not gauge sensitivity corrected). The equiatomic composition was reached by adjusting the elemental targets under the sputtering beam geometrically. The thickness of the thin film sample was found to be around 1.5 microns as measured after Focused Ion Beam (FIB) sectioning.

A FEI Quanta FEG250 Scanning Electron Microscope (SEM) was used for the material surface observations. The chemical composition of the samples was investigated by Energy-Dispersive X-ray spectroscopy (EDX), Oxford Instruments. X-Ray Diffraction (XRD) was performed on a Bruker D2 Phaser instrument. Measurement Center 4.0 software was used to examine the crystal structure. Selected Area Diffraction (SAD) and imaging in Transmission Electron Microscope (TEM) were used to analyse atomic structure in detail.

Potentiodynamic polarization tests were performed in a three-electrode cell system, with the specimens as working electrodes (exposed area of $0.5 \mathrm{~cm}^{2}$ ), saturated calomel electrode (SCE) as reference electrode and platinum as the counter electrode. The electrolyte used was an aqueous $3.5 \% \mathrm{NaCl}$ solution. The measurements were taken at room temperature under atmospheric pressure. Before each experiment, the open circuit potential (OCP) was measured for $30 \mathrm{~min}$ to reach a stable potential. The current and potential were measured using a Autolab potentiostat controlled by Nova 1.10 software. Additionally, according to ASTM standard, the potentiodynamic tests were conducted at a scan rate of $1 \mathrm{mV} / \mathrm{s}$. Electrochemical parameters such as corrosion current density ( $\left.\mathrm{i}_{\text {corr }}\right)$, corrosion potential $\left(\mathrm{E}_{\text {corr }}\right)$, and passivation regions were acquired by evaluating polarization curves.

Nanohardness of FeCrMnNiC amorphous HEATF was evaluated by Nanoindentation system from Micro Materials Ltd, UK. The maximum load applied was $50 \mathrm{mN}$.

\section{Results and Discussion}

\section{Microstructure}

Figure 1 (A) shows the BSED (backscatter) SEM image of FeCrMnNiC high entropy thin film alloy. The absence of any topographical and electron channelling contrasts is the first indication of the film amorphous nature. Figure 1B EDX analysis represents the chemical composition of $\mathrm{FeCrMnNiC}$ thin film alloy confirming the equiatomic ratio. 
(A)

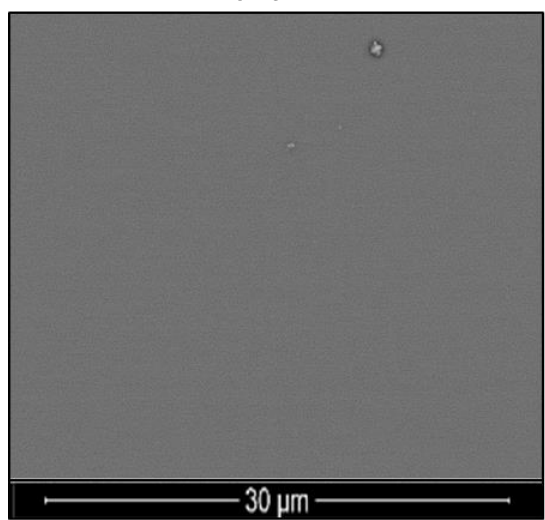

(B)

\begin{tabular}{|l|l|l|}
\hline Element & Weight\% & Atomic\% \\
\hline C K & 5.46 & 20.19 \\
\hline Cr L & 22.36 & 19.10 \\
\hline Mn L & 23.76 & 19.21 \\
\hline Fe L & 25.64 & 20.40 \\
\hline Ni L & 27.78 & 21.09 \\
\hline Totals & 100.00 & \\
\hline
\end{tabular}

Figure 1: Surface microstructure of FeCrMnNiC amorphous high entropy thin film alloy (A) and elemental composition (B).

Elemental EDX mapping in Figure. 2 shows uniform distribution of $\mathrm{FeCrMnNiC}$ alloy elements. The data confirm that the $\mathrm{Cr}, \mathrm{Mn}, \mathrm{Fe}$ and $\mathrm{Ni}$ elements present in matrix are distributed homogeneously.

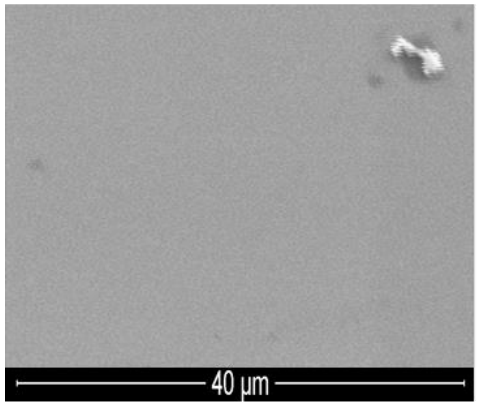

Electron Image

\section{$\mathrm{Mn}$}

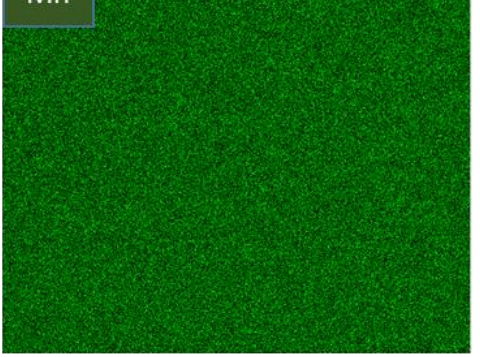

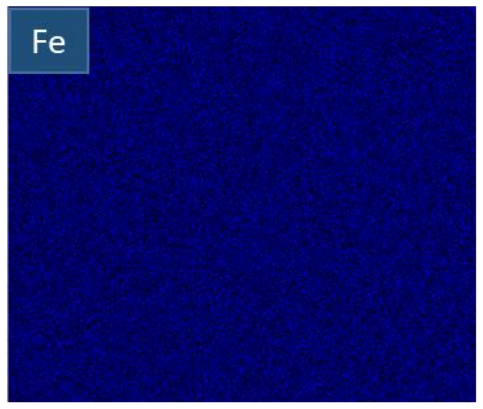

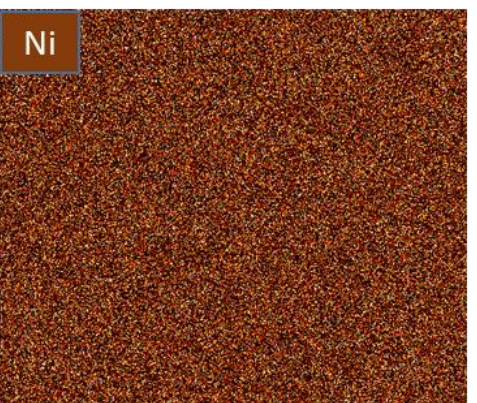

$\mathrm{Cr}$

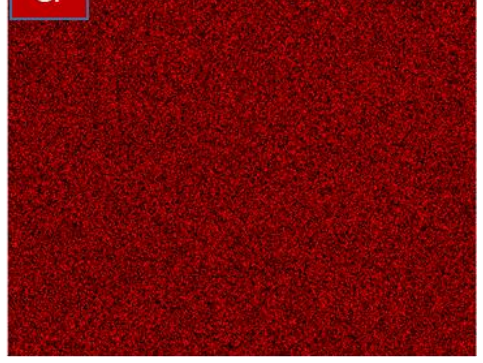

Figure 2: Elemental EDX mapping of $\mathrm{FeCrMnNiC}$ thin film.

XRD spectrum (Fig.3) confirms that FeCrMnNiC high entropy thin film alloy has an amorphous structure. The spectrum has only a peak at around $42^{0}$ and it does not demonstrate any sharp diffraction peaks. The other peak in $20^{\circ}$ region is referred to the glass substrate. 


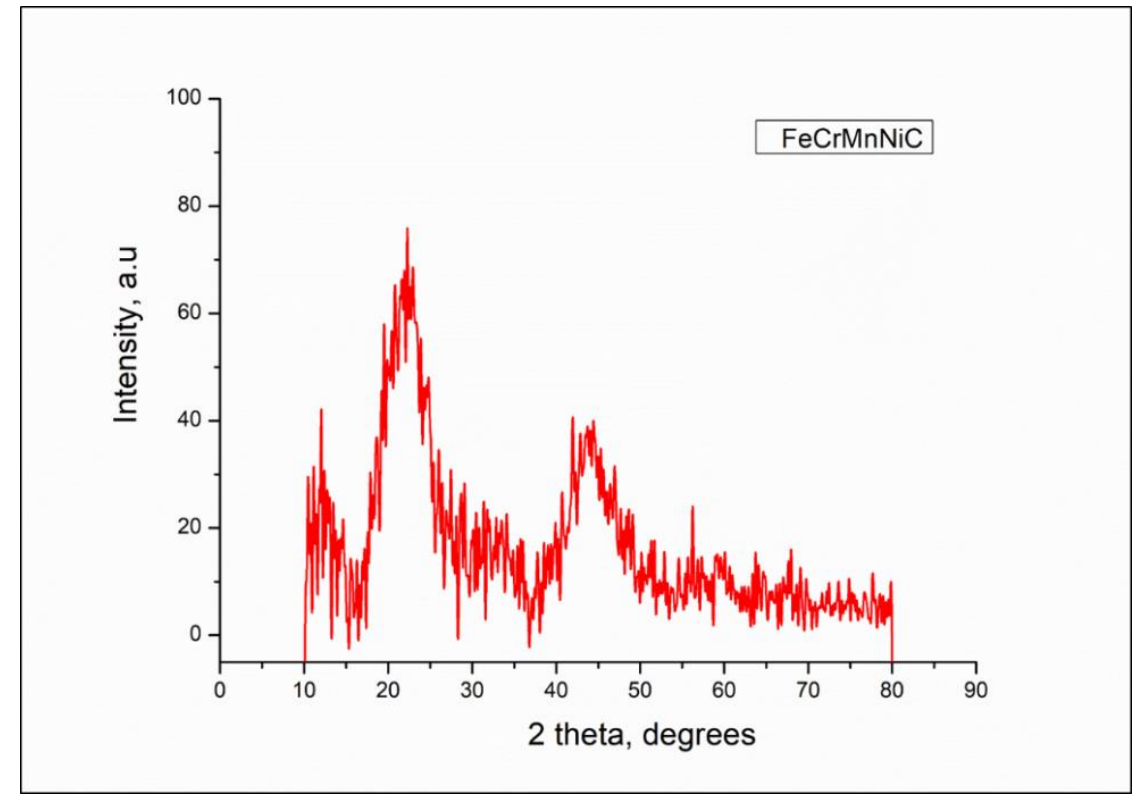

Figure 3: XRD pattern of amorphous FeCrMnNiC high entropy thin film alloy.

Transmission Electron Microscopy (Fig.4) shows uniform image contrast without any diffraction or mass thickness contrast. The SAED only shows the typical broad diffraction ring typical of amorphous structures without any trace of nanocrystallinity. All the above demonstrates that the films are dense, uniform and amorphous.

(a)

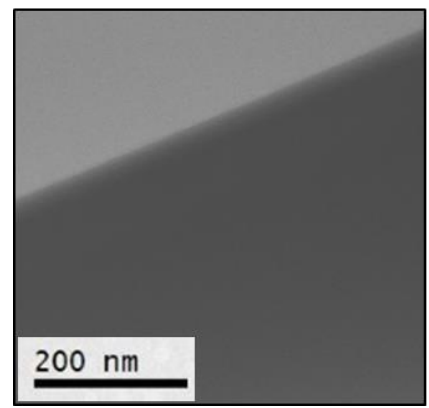

(b)

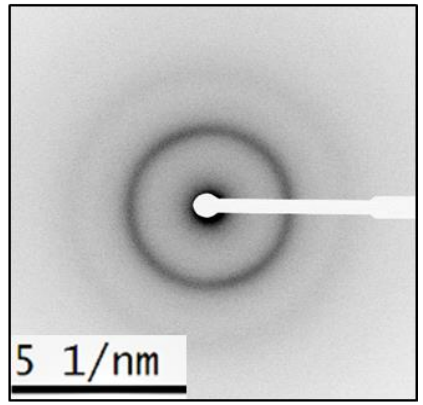

Figure 4: BFTEM image (a) and its SAED (b) of FeCrMnNiC thin film deposited on silica substrate at room temperature. The film on the image is in the right-bottom corner.

Thin films deposited at low temperature (close to room temperature) do not have sufficient diffusion for possible phase separation in many cases and are "frozen" in the not thermodynamically equilibrium state. In some respect this might be an advantage as compared to bulk (for instance arc melting) synthesis. Indeed, this was demonstrated before, there was no phase separation and segregation in synthesised $\mathrm{CrCoCuNiFe}$ thin films as compared to bulk $\mathrm{CrCoCuNiFe,} \mathrm{which} \mathrm{was} \mathrm{found} \mathrm{to} \mathrm{be} \mathrm{two} \mathrm{phase} \mathrm{alloy} \mathrm{[37].}$

Even if films are deposited at the elevated substrate temperature the temperature might not be high enough to produce crystallization rearrangement of amorphous, as immediately deposited, 
structure. For instance, this was the case in an earlier work [38], when AlCoCrCuFeNi thin film deposited by magnetron sputtering at temperatures in the range $110-510{ }^{\circ} \mathrm{C}$ was still not crystalline. In our case large atomic size differences and rapid cooling during deposition can assist in preservation of amorphous state as was predicted earlier [2, 39].

\section{Electrochemical tests}

The potentiodynamic polarisation curve results for $\mathrm{FeCrMnNiC}$ equiatomic high entropy amorphous thin film in a comparison with 304 SS are shown on Fig.5. The numerical corrosion parameters such as corrosion current density and corrosion potential of the amorphous HEA against $304 \mathrm{SS}$ are provided in Table 1. The results show that $\mathrm{FeCrMnNiC}$ amorphous high entropy alloy and $304 \mathrm{SS}$ both have high corrosion resistance in $3.5 \% \mathrm{NaCl}$ solution, but better results are seen for the amorphous HEA thin film alloy.

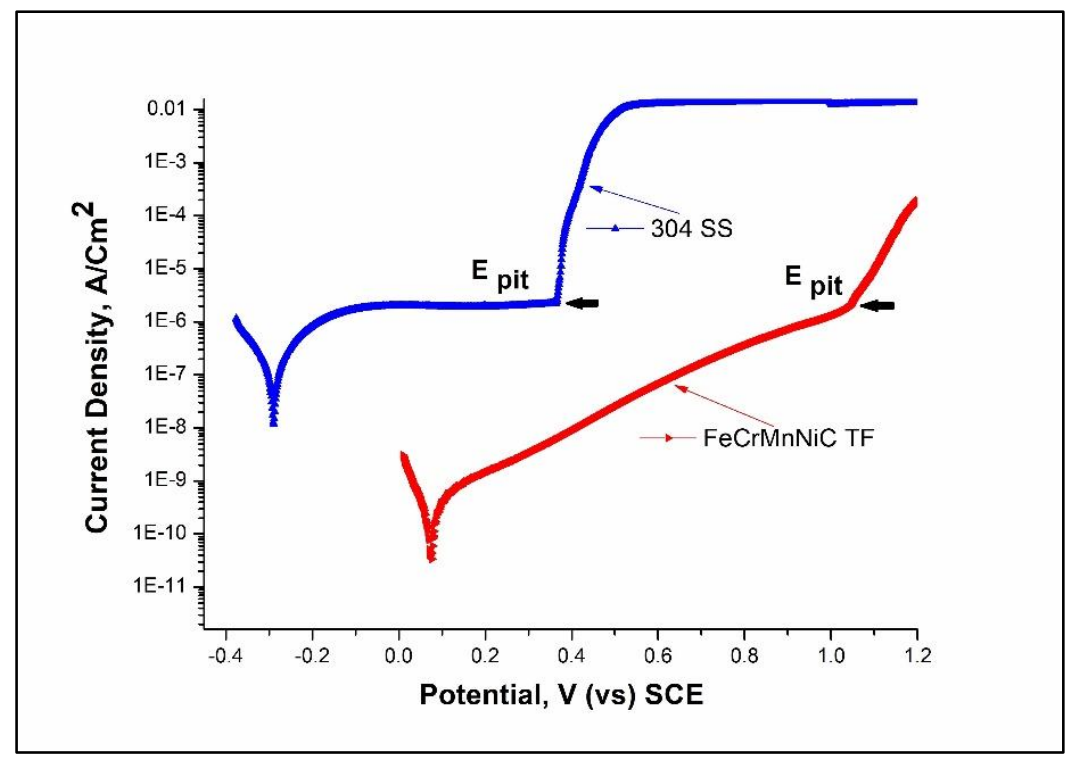

Figure 5: Potentiodynamic polarisation curve of $\mathrm{FeCrMnNiC}$ amorphous high entropy thin film \& $304 \mathrm{SS}$ in aqueous $3.5 \% \mathrm{NaCl}$ solutions at room temperature

Table 1: Corrosion parameters of FeCrMnNiC amorphous HETF and different types of HEAs tested in $3.5 \% \mathrm{NaCl}$ solution.

\begin{tabular}{|c|c|c|c|c|c|}
\hline Sample & Type of HEA & $i_{\text {corr, }} A / \mathrm{cm}^{2}$ & $E_{\text {corr, }} V$ & $E_{p i t, V}$ & reference \\
\hline FeCrMnNiC & Coating & $2.5 * \mathrm{E}^{-10}$ & 0.07 & 1.04 & Current study \\
\hline 304 SS & Bulk & $1.1 * E^{-7}$ & -0.29 & 0.36 & Current study \\
\hline CrMnFeCoNi & Coating & $1.1 * \mathrm{E}^{-7}$ & -0.09 & 0.22 & {$[28]$} \\
\hline CoCrFeNiW & - & $1.4 * \mathrm{E}^{-5}$ & -0.99 & -0.37 & {$[40]$} \\
\hline $\mathrm{CoCrFeNiW}_{0.5} \mathrm{Mo}_{0.5}$ & - & $1.4 * \mathrm{E}^{-6}$ & -1.02 & -0.26 & [40] \\
\hline
\end{tabular}




\begin{tabular}{|c|c|c|c|c|c|}
\hline$(\mathrm{CoCrFeNi})_{95} \mathrm{Nb}_{5}$ & - & $7.2 * E^{-6}$ & -0.37 & 0.26 & [41] \\
\hline AlTiCrNiTa & - & $3.2 * E^{-8}$ & -0.26 & $\mathrm{~N} / \mathrm{A}$ & [42] \\
\hline $\mathrm{FeCoNiCr}$ & Bulk & $3.1 * E^{-8}$ & -0.26 & 0.31 & [31] \\
\hline FeCoNiCrCu & - & $1.3 * \mathrm{E}^{-6}$ & -0.33 & 0.08 & [31] \\
\hline AlCoCrCuFe & - & $9.7 * E^{-7}$ & -0.25 & -0.13 & [32] \\
\hline AlTiVCrSi & - & $1.7 * \mathrm{E}^{-7}$ & -0.49 & -0.01 & {$[32]$} \\
\hline $\mathrm{CoCrFeNi}_{2}$ & - & $1.3 * \mathrm{E}^{-7}$ & -0.29 & $\mathrm{~N} / \mathrm{A}$ & [43] \\
\hline CoCrFeNi2Mo 0.25 & - & $1.3 * \mathrm{E}^{-7}$ & -0.26 & $\mathrm{~N} / \mathrm{A}$ & [43] \\
\hline
\end{tabular}

According to electrochemical theory for analysing corrosion behaviour, the material is resistant to corrosion if it exhibits a small corrosion current density ( $\left.\mathrm{I}_{\text {corr }}\right)$ with high, cathodic, corrosion potential $\left(\mathrm{E}_{\text {corr }}\right)[44]$. As can be seen from the polarisation curve, the corrosion potential $\left(\mathrm{E}_{\text {corr }}\right)$ of HEATF $(0.07 \mathrm{~V})$ is significantly more cathodic than that of $304 \mathrm{SS}(-0.29 \mathrm{~V})$. The corrosion current density $\left(\mathrm{i}_{\text {corr }}\right)$ of HEATF $\left(2.5^{*} \mathrm{E}^{-10}\right)$ is lower than $304 \mathrm{SS}\left(1.1^{*} \mathrm{E}^{-7}\right)$. In addition, a larger passivation potential area exists in HEATF compared to $304 \mathrm{SS}(0.93 \mathrm{~V}$ vs $0.65 \mathrm{~V})$. Even at the pitting potential, the corrosion current for HETF is lower than for $305 \mathrm{SS}$. In summary, the FeCrMnNiC amorphous HEATF alloy has excellent corrosion resistance - much better than $304 \mathrm{SS}$ in $3.5 \% \mathrm{NaCl}$ solution. This can be attributed to the main four effects of high entropy alloys; entropy effect, cocktail effect, sluggish diffusion effect, and lattice distortion effect [33, 45]. Also, the equiatomic composition and the uniform structure without element segregation which led to the homogeneous microstructure of alloy [29]. In addition, low corrosion rate is due to the absence of grain boundaries in the amorphous film, as usually corrosion occurs preferably at grain boundaries [46, 47]. It is also possible to suggest that there is an effect of elements with excellent corrosion resistance such as chromium and nickel in the composition, which can form a protective passivation layer preventing further corrosion on the alloy surface. The latter, is in line with corrosion resistance in HEAs suggested earlier [48]. In addition, adding metalloids such as carbon to the alloy is likely enhances the corrosion resistance [34]. As sintered, the FeCrMnNiC amorphous HEATF exhibited better corrosion resistance than many high entropy alloys coatings such as: CrMnFeCoNi [28]; CoCrFeNiW, $\mathrm{CoCrFeNiW}_{0.5} \mathrm{Mo}_{0.5}$ [40]; (CoCrFeNi) ${ }_{95} \mathrm{Nb}_{5}$ [41] and AlTiCrNiTa [42]. Also, high entropy bulk alloys such as: $\mathrm{FeCoNiCr}$ and $\mathrm{FeCoNiCrCu}$ [31]; AlCoCrCuFe and AlTiVCrSi [32]; $\mathrm{CoCrFeNi}_{2}$ and $\mathrm{CoCrFeNi}_{2} \mathrm{Mo}_{0.25}$ [43]. Corrosion parameters of all mentioned alloys are provided in table 1 .

\section{Nanomechanical properties}

The film hardness was measured by nanoindentation. The maximum plastic penetration depth was limited to below $500 \mathrm{~nm}$ to avoid significant influence from the substrate. Incremental loading was used to account for the influence of penetration depth on the measured mechanical properties. The Figure 6 shows series of nanoindentation curves. The average film hardness is $12.3 \pm 0.5 \mathrm{GPa}$. The reduced Young's modulus is estimated by the modulus approximation to zero load (in line with ISO14577 part 4 standard) as shown on Fig.7. The reduced Young's modulus is estimated to be $222 \pm 7 \mathrm{GPa}$. 


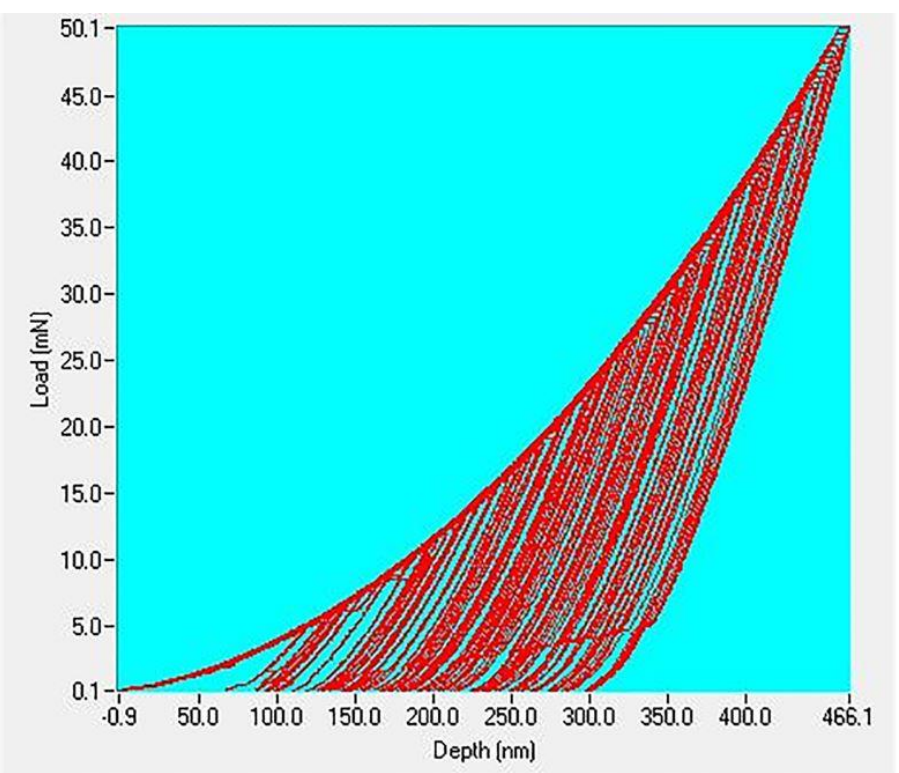

Figure 6. Nanoindentation data set for FeCrMnNiC amorphous HEATF.

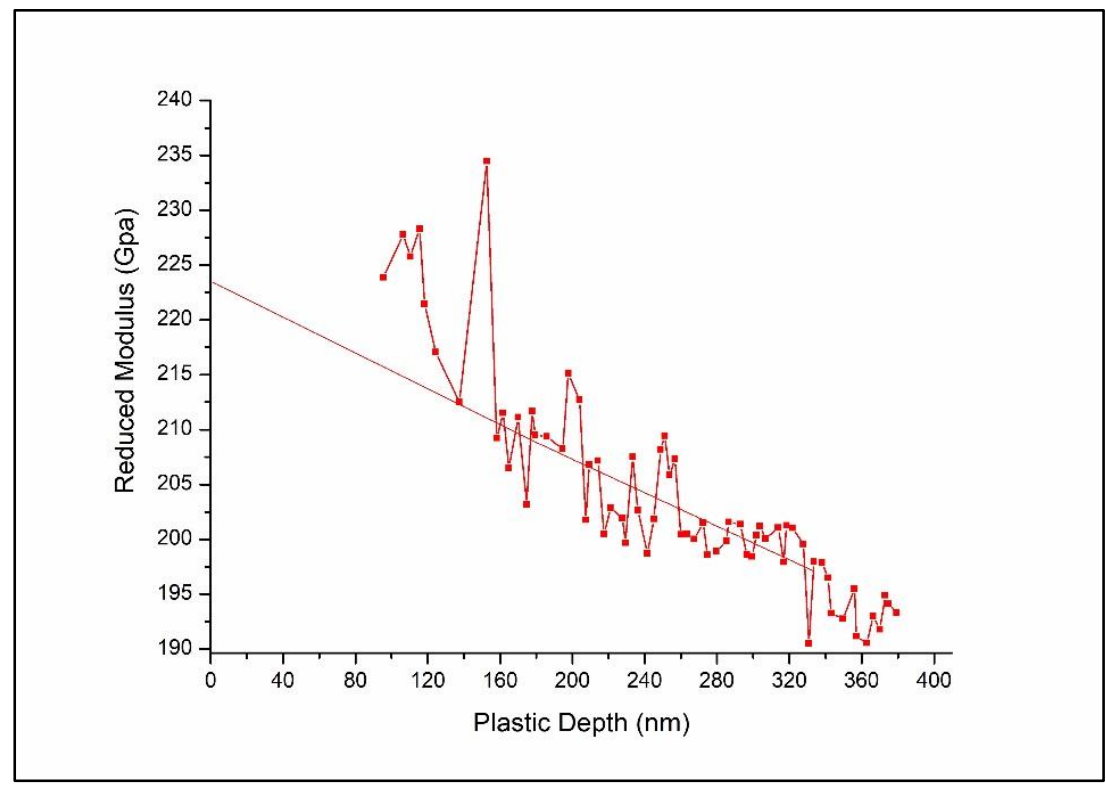

Figure 7. Reduced modulus value over plastic depth. Approximation to zero plastic depth was done by a linear fit.

The films mechanical properties are higher compared to other amorphous pure metallic systems. For instance, the films are harder than TiVCrAlZr [49] and FeCoNiCuVZrAl [50] HEATF deposited by reactive radio-frequency and direct current magnetron sputtering respectively. The nanohardness and reduced Young's Modulus $[49,50]$ for TiVCrAlZr and FeCoNiCuVZrAl were recorded to be 8.2, 8.6 GPa and 128.9 and $153 \mathrm{GPa}$ respectively. 
Addition of covalent bonding elements leads to enhanced mechanical properties. For instance, addition of nitrogen to TiVCrAlZr [49] and FeCoNiCuVZrAl [50] thin films resulted in increment in hardness and reduced Young's modulus which were recorded to be 11, $12 \mathrm{GPa}$ and $151 \mathrm{GPa}, 166 \mathrm{GPa}$, respectively. This superior hardness and reduced Young's modulus in present study and, in nitride films $[49,50]$ compared to purely metallic high-entropy alloy thin films can be attributed to additional hardening effect due to extensive lattice distortion by presence of carbon or nitrogen.

\section{Conclusions}

- An equiatomic FeCrMnNiC thin film was successfully synthesised by ion bean sputter deposition.

- The FeCrMnNiC thin film is amorphous

- The film has uniform composition and atomic arrangement structure with no element segregation.

- The FeCrMnNiC this film exhibits high resistance to corrosion and outperforms 304 $\mathrm{SS}$ in aqueous $3.5 \% \mathrm{NaCl}$ solutions at room temperature under atmospheric pressure.

- The alloy demonstrates high hardness of $12.3 \mathrm{Gpa}$ and reduced Young's modulus of $222 \mathrm{GPa}$.

- It is proposed that the $\mathrm{FeCrMnNiC}$ amorphous thin film can be used for protection of mild steel in demanding environments such as oil and gas exploration and procession. 


\section{References}

1. Cantor, B., et al., Microstructural development in equiatomic multicomponent alloys. Materials Science and Engineering: A, 2004. 375: p. 213-218.

2. Miracle, D.B. and O.N. Senkov, A critical review of high entropy alloys and related concepts. Acta Materialia, 2017. 122: p. 448-511.

3. Yeh, J.W., et al., Nanostructured high-entropy alloys with multiple principal elements: novel alloy design concepts and outcomes. Advanced Engineering Materials, 2004. 6(5): p. 299303.

4. Yeh, J.-W., et al., Formation of simple crystal structures in Cu-Co-Ni-Cr-Al-Fe-Ti-V alloys with multiprincipal metallic elements. Metallurgical and Materials Transactions A, 2004. 35(8): p. 2533-2536.

5. Huang, P.K., et al., Multi-principal-element alloys with improved oxidation and wear resistance for thermal spray coating. Advanced Engineering Materials, 2004. 6(1-2): p. 74-78.

6. Mary, S.J., N. Rajan, and R. Epshiba, High entropy alloys properties and its applications-An over view. European Chemical Bulletin, 2015. 4(4-6): p. 279-284.

7. Murty, B.S., et al., High-entropy alloys. 2019: Elsevier.

8. Ruta, B., E. Pineda, and Z. Evenson, Relaxation processes and physical aging in metallic glasses. Journal of Physics: Condensed Matter, 2017. 29(50): p. 503002.

9. Klement, W., R. Willens, and P. Duwez, Non-crystalline structure in solidified gold-silicon alloys. Nature, 1960. 187(4740): p. 869-870.

10. Luborsky, F., Amorphous metallic alloys. Butterworth and Co. Ltd., 1983, 1983: p. 534.

11. Schuh, C.A., T.C. Hufnagel, and U. Ramamurty, Mechanical behavior of amorphous alloys. Acta Materialia, 2007. 55(12): p. 4067-4109.

12. Wang, D., et al., Bulk metallic glass formation in the binary Cu-Zr system. Applied Physics Letters, 2004. 84(20): p. 4029-4031.

13. Telford, M., The case for bulk metallic glass. Materials today, 2004. 7(3): p. 36-43.

14. Reddy, K.V. and S. Pal, Evaluation of glass forming ability of Zr-Nb alloy systems through liquid fragility and Voronoi cluster analysis. Computational Materials Science, 2019. 158: $p$. 324-332.

15. Wu, G., et al., Novel multilayer structure design of metallic glass film deposited $\mathrm{Mg}$ alloy with superior mechanical properties and corrosion resistance. Intermetallics, 2015. 62: p. 22-26.

16. Gao, X., et al., High mixing entropy bulk metallic glasses. Journal of Non-Crystalline Solids, 2011. 357(21): p. 3557-3560.

17. Wang, W., High-entropy metallic glasses. Jom, 2014. 66(10): p. 2067-2077.

18. $\mathrm{Xu}, \mathrm{Y}$., et al., Formation and properties of Fe25Co25Ni25 ( $P, C, B$, Si) 25 high-entropy bulk metallic glasses. Journal of Non-Crystalline Solids, 2018. 487: p. 60-64.

19. Ding, H. and K. Yao, High entropy Ti20Zr20Cu20Ni20Be20 bulk metallic glass. Journal of NonCrystalline Solids, 2013. 364: p. 9-12.

20. Schuegraf, K.K., Handbook of thin-film deposition processes and techniques: principles, methods, equipment, and applications. 1988: Noyes Data Corporation/Noyes Publications.

21. Wasa, K., M. Kitabatake, and H. Adachi, Thin film materials technology: sputtering of control compound materials. 2004: Springer Science \& Business Media.

22. Kumar, N., et al., Friction stir processing of a high entropy alloy Al 0.1 CoCrFeNi. Jom, 2015. 67(5): p. 1007-1013.

23. Reddy, S., et al., Nanostructuring with Structural-Compositional Dual Heterogeneities Enhances Strength-Ductility Synergy in Eutectic High Entropy Alloy. Scientific reports, 2019. 9(1): p. 1-9. 
24. Sunkari, U., et al., Tuning nanostructure using thermo-mechanical processing for enhancing mechanical properties of complex intermetallic containing CoCrFeNi2. 1Nbx high entropy alloys. Materials Science and Engineering: A, 2020. 769: p. 138489.

25. Su, J., D. Raabe, and Z. Li, Hierarchical microstructure design to tune the mechanical behavior of an interstitial TRIP-TWIP high-entropy alloy. Acta Materialia, 2019. 163: p. 40-54.

26. Li, Z. and D. Raabe, Strong and ductile non-equiatomic high-entropy alloys: design, processing, microstructure, and mechanical properties. Jom, 2017. 69(11): p. 2099-2106.

27. Zhao, S., et al., Microstructure and chloride corrosion property of nanocrystalline AlTiCrNiTa high entropy alloy coating on X80 pipeline steel. Surface and Coatings Technology, 2019. 375: p. 215-220.

28. Ye, Q., et al., Microstructure and corrosion properties of CrMnFeCoNi high entropy alloy coating. Applied Surface Science, 2017. 396: p. 1420-1426.

29. Qiu, X.-w., et al., Corrosion performance of Al2CrFeCoxCuNiTi high-entropy alloy coatings in acid liquids. Journal of Alloys and Compounds, 2017. 708: p. 353-357.

30. Chen, Y., et al., Microstructure and electrochemical properties of high entropy alloys-a comparison with type-304 stainless steel. Corrosion science, 2005. 47(9): p. 2257-2279.

31. Hsu, Y.-J., W.-C. Chiang, and J.-K. Wu, Corrosion behavior of FeCoNiCrCux high-entropy alloys in 3.5\% sodium chloride solution. Materials Chemistry and Physics, 2005. 92(1): p. 112-117.

32. Qiu, Y., et al., Corrosion characteristics of high entropy alloys. Materials Science and Technology, 2015. 31(10): p. 1235-1243.

33. Shi, Y., B. Yang, and P. Liaw, Corrosion-resistant high-entropy alloys: A review. Metals, 2017. 7(2): p. 43.

34. Henderson, R.S., G.A. Shreve, and M.A. Tenhover, Enhanced corrosion resistant amorphous metal alloy coatings. 1989, Google Patents.

35. Malinovskis, P., et al., Synthesis and characterization of multicomponent (CrNbTaTiW) C films for increased hardness and corrosion resistance. Materials \& Design, 2018. 149: p. 51-62.

36. Vishnyakov, V., et al., Ion sputter-deposition and in-air crystallisation of Cr2AIC films. Vacuum, 2014. 100: p. 61-65.

37. An, Z., et al., Solid-solution CrCoCuFeNi high-entropy alloy thin films synthesized by sputter deposition. Materials Research Letters, 2015. 3(4): p. 203-209.

38. Dolique, V., et al., Thermal stability of AlCoCrCuFeNi high entropy alloy thin films studied by in-situ XRD analysis. Surface and Coatings Technology, 2010. 204(12-13): p. 1989-1992.

39. Sheng, W., et al., Nano-crystallization of high-entropy amorphous NbTiAlSiWxNy films prepared by magnetron sputtering. Entropy, 2016. 18(6): p. 226.

40. Shang, C., et al., CoCrFeNi (W1-xMox) high-entropy alloy coatings with excellent mechanical properties and corrosion resistance prepared by mechanical alloying and hot pressing sintering. Materials \& Design, 2017. 117: p. 193-202.

41. Wang, W., et al., Microstructure and Corrosion behavior of (CoCrFeNi) 95Nb5 high-entropy alloy coating fabricated by plasma spraying. Materials, 2019. 12(5): p. 694.

42. Wang, H.-d., et al., Microstructure and corrosion behaviour of AlCoFeNiTizr high-entropy alloy films. Surface Engineering, 2020. 36(1): p. 78-85.

43. Rodriguez, A.A., et al., Effect of molybdenum on the corrosion behavior of high-entropy alloys $\mathrm{CoCrFeNi2}$ and $\mathrm{CoCrFeNi2MoO} .25$ under sodium chloride aqueous conditions. Advances in Materials Science and Engineering, 2018. 2018.

44. Kelly, R.G., et al., Electrochemical techniques in corrosion science and engineering. 2002: CRC Press.

45. Jien-Wei, Y., Recent progress in high entropy alloys. Ann. Chim. Sci. Mat, 2006. 31(6): p. 633648.

46. Gan, Y., et al., Multi-layer laser solid forming of Zr65Al7. 5Ni10Cu17. 5 amorphous coating: Microstructure and corrosion resistance. Optics \& Laser Technology, 2015. 69: p. 17-22. 
47. Li, R., et al., Structure and corrosion resistance properties of $\mathrm{Ni}-\mathrm{Fe}-\mathrm{B}-\mathrm{Si}-\mathrm{Nb}$ amorphous composite coatings fabricated by laser processing. Journal of alloys and compounds, 2013. 580: p. 327-331.

48. Tian, Y., et al., Microstructure and corrosion property of CrMnFeCoNi high entropy alloy coating on Q235 substrate via mechanical alloying method. Surfaces and Interfaces, 2019. 15: p. $135-140$.

49. Chang, Z.-C., et al., Characteristics of TiVCrAlZr multi-element nitride films prepared by reactive sputtering. Nuclear Instruments and Methods in Physics Research Section B: Beam Interactions with Materials and Atoms, 2010. 268(16): p. 2504-2509.

50. Liu, L., et al., Dense and smooth amorphous films of multicomponent FeCoNiCuVZrAl highentropy alloy deposited by direct current magnetron sputtering. Materials \& Design, 2013. 46: p. 675-679. 